\title{
An Ethnographic Qualitative Study On The Malaysian Preschool And Special Needs Children's Home And School Reading Habits
}

\author{
Kamarudin, D. ${ }^{1}$, Hussain, Y. ${ }^{2}$, Applegate, E. B ${ }^{3}$, Yasin, M. H. M. ${ }^{4}$ \\ ${ }^{1}$ Universiti Malaysia Pahang, Malaysia ${ }^{2}$ Southeast Asian Ministers of Education Organization \\ Centre for Special Educational Needs ${ }^{3}$ Western Michigan University, United States of America \\ ${ }^{4}$ Universiti Kebangsaan Malaysia, Malaysia
}

Corresponding email: yanakamarudin@ump.edu.my

\begin{abstract}
This research is a qualitative research, exploring the reasons behind why the level of literacy in Malaysian students are quite low. The research delved into identifying ways to implement reading habits to preschool and special education children. The purpose which guides this research is that according to thestaronline.com on August $18^{\text {th }}$ 2012, an online version of The Star newspaper from Malaysia, the average Malaysian only reads 2 books per year in 1996. This has made the Department of Higher Education worry about the level of proficiency in Malaysian students. This is a qualitative research utilizing open ended questionnaires and interviews as the main form of data collection. Parents were asked to document their open ended questionnaire and participate in an interview session in regards to their home reading habits with their children. In descending order, the themes found most important were implemented into school curriculum, parents should play a bigger role in children's reading habits and early exposure. Results also indicated that parents in Malaysia do face problems when trying to implement reading culture into their daily lives.
\end{abstract}

Keywords: Children, Qualitative research, Reading habit, Malaysia, Education

DOI: 10.20961/ijpte.v\%vi\%i.19902 


\section{INTRODUCTION}

Literacy, as defined by UNESCO is a person's ability to understand, identify, interpret and communicate printed and written materials according to their context (Chew, 2012). The purpose which guides this research is that according to thestaronline.com on August $18^{\text {th }}$ 2012, an online version of The Star newspaper from Malaysia, Malaysians only reads 2 books per year in 1996. This has made the Department of Higher Education worry about the level of proficiency in Malaysian students, according to the Deputy of Higher Education Minister at the time, Datuk Dr. Hou Kok Chung. Also, according to Hou, 60\% of public university applicants only possess a band 3 and below in their Malaysian University English Test (MUET). The highest band in the Malaysian University English Test (MUET) is a band 6 (The Star Online, 2012). This statement is aligned with Chew's (2012) study where she mentioned that $7.7 \%$ of primary school students, which consisted of 115000 students in Phase I have not mastered reading, writing and arithmetic, which contributed to a large percentage of dropouts later on in their schooling years.

Numerous attempts at boosting more reading in Malaysians has been attempted, but to little or no avail. Therefore the researchers thought that the problem should be delved from the root and try to be implemented reading from preschool level. Children seek knowledge naturally. It is in this early stage that their minds grow. Whether it's dinosaurs, ABC's, the latest technology or children's activity, they are often guided by their need to know. It is our job as educators and parents to nurture this need. The most engaging classroom, the ones where children are actively participating in classroom discussions and projects aren't just fiddling around with sounds associated with printed letters. There will of course be ABC's and books all over the room, but these materials alone are not the drivers of the activities. We need to implement them in order for children to be able to actively be knowledge seekers (Neuman, 2010).

Children who are at risk for reading failure tend to be less motivated to engage in reading tasks where they hold more negative self-concepts (Chapman, 1988; Chapman, Tunmer, \& Prochnow, 2000; Stanovich, Jordan, \& Perot, 1998). Researchers have found that these children feel more helpless, display less emotional self-regulation and tend to avoid reading activities compared to their peers. Children at risk for reading failure also tend to be characterized as "inactive learners". Some researchers have also recently proposed that poor motivation may be a defining feature of reading failure. Poor motivation is seen as an important factor because of its link to reading practice. Children who avoid frequent reading practice rarely become skilled readers. This is due to the fact that frequent reading is considered critical in increasing a child's word recognition, vocabulary, and verbal fluency, reading comprehension and general knowledge skills (Morgan, Fuchs, Compton, Cordray, \& Fuchs, 2008). A study conducted by Wigfield and Guthrie (1997) also found that children who are less motivated read only one third compared to their more motivated peers.

Researchers studying early literacy behaviours have observed that storybook reading and sharing between adults and children served as a stepping stone for 
children to learn how to read. A lot of research has also found that there are a lot of benefits to reading storybooks some of which are oral language development, and structured conversational exchange between adults and younger children (Kabuto, 2010). Early childhood reading is considered beneficial as it contributes for early language and literacy development (Morgan, 2005). A study done by Paley (1981) found that children's use of storytelling in the classroom serves as an extension of their play, thus adding more power in its potential influence in all areas of children's development. In Paley's recent study, she stated that although storytelling curriculum is merely a reading curriculum, but its purpose serves a much deeper purpose than that. There is a link between storytelling and later academic achievement in general. She cautions us not to forget that fantasy play, which includes the stories that are made up by the children are the glue that binds all early academic learning. Fantasy play is not a distraction, but rather helps children achieve the goal of having an open mind, whether in more storytelling or in formal lessons (Paley, 2004). Through fantasy play children are able to separate thought from action, thus furthering their thinking skills by separating real and make believe (Cooper, 2005). Story reading not only benefits the child that it is being read to, but it also benefits the other siblings in the home with the child, as they interact with each other. A study conducted by Gregory (2001) also found that an older sibling will mediate the younger child's literacy learning by mimicking and blending features of how language and literacy is used in the household and by their teachers at school.

Many people might not notice how important story telling curriculum is, as it does not seem to address any particular reading approach, but its primary aim is to actually provide a forum where young children could tell and act out a story of significance to themselves and the class. Through story telling children are able to develop their oral language through expression, home language, and vocabulary and sentence patterns. They are also able to narrate forms by having knowledge of how the story develops, what stories are composed of, sequencing, and plot development of the story, characterization, and use of imagination. Children are also able to understand the print concept through story reading by understanding how print functions by the spaces between words, letters, and punctuation (Cooper, 2005).

A research conducted by Xue and Meisels (2004) on early literacy instructional approach found that when holding all other characteristics and ability constant, phonics and integrated language arts activities promotes growth in children's classroom learning among kindergarten children. Xue and Meisels (2004) also found that after controlling for family social economic status and other child characteristic, both phonics instruction (story telling) and integrated language arts both have beneficial effects on teachers' ratings of children's achievement and approaches to learning among children.

Children not only benefit from reading while at school, but they benefit more if parents practiced reading to their children while at home. A study conducted by Torr (2004) looked at how children who cannot yet read and write in a conventional manner respond to being read at home through picture books. The study mainly focuses on parents' interaction with their children at home. The 
study looked at the systematic differences in the way children interact with their teachers on the text compared to the children who are interacting with their mother.

According to Morgan (2005), children who read with parents not only do more than read the text, and researchers have identified specific behaviours believed to be particularly effective in encouraging their language development and literacy skills as this is the time when children are like sponges and absorb everything. When children read with parents, the parents might refocus the child's attention to the reading material, where it might be harder to do that in a class full of children. Parents might also prompt children to answer certain questions when reading, thus bringing back their attention to the book. Interacting with the child based on the text, such as questioning them about the illustration, or the narrative could promote vocabulary development, while praising them raises their self-esteem so that they would enjoy more reading and won't be too afraid to raise their voice (Morgan, 2005).

It is common to read out loud to children as parents, educators, policy makers and politicians share the common belief that reading to children makes a difference in children's literacy development. Many children learn to read effortlessly but 10\%of children have difficulty acquiring reading skills and would need additional support (Swanson, Vaughn, Wanzek, Petscher, Heckert, Cavanaugh, Kraft, \& Tackett, 2011). Although educators and parents would need to spot early on which children would need additional support, it is also important to start reading early to children to help promote reading readiness and encourage children to love reading. Book exposure is considered to be a major source for developing children's vocabulary as the nature of the text and the number of times a book is reread seems to be important contributors to young children's vocabulary development. Children are also able to foster print knowledge which would lead to children feeling more attracted to letters and sounds in books (Mol, Bus, \& Jong, 2009).

\section{METHODOLOGY}

According to Gall, Gall and Borg (2014) the methodological decision is extremely important as it would shape the nature of the data as well as how the data is to be collected, analyzed and interpreted. All these decisions would also have an impact on the bias in the study (Gall et al., 2014; Kamarudin, 2017). The design used for this research is a qualitative methodology, using the ethnographic approach, as the researcher would like to understand the matter in depth, looking at it from a cultural perspective, specifically, the Malaysian perspective (Kamarudin, 2017).

This research utilized open ended questionnaires and interviews as the data collection method for both parents of preschool children and special education children. Parents were be asked to document in their questionnaires about their reading habits at home with their children. In this research, the researcher used questionnaires for the entire group. The questionnaires were filled by parents where they were asked to participate by filling in a questionnaire on their home reading habits. Some studies might be a burden to participants, where participants 
might find themselves with a heavy set of questionnaires or they might need to participate more than once for a study. Although these studies might yield great results, the participants might not want to participate if they feel as if it would be too much of a burden to them. Due to this, the researcher would need to communicate the rationale behind these rigorous items and how important it would be to the study, or in this case, to their children's future (Braverman \& Arnold, 2008). Interview questions were developed for the interview protocol with the guidance of SEAMEO SEN's director, Dr. Yasmin Hussain. For example, parents may discuss they do not have time to read with this children. If this were found through coding and analysis, from the diary entry in the data, a specific interview question regarding time for reading would be generated. In short, the interview questions were meant to explore, further codes and themes from the analysis of the questionnaire data.

\section{Subject Selection}

200 open ended questionnaires were sent out to parents divided equally between parents of special education children and preschool children, of which 129 were returned. Twelve parents of those participant were recruited for this study through purposeful and snowball sampling. Parents who were between the ages of 21 and 60 years old with children who ranged from four year old to six year olds were recruited for preschool children, whereas for special education children, parents between the ages of 21 and 60 were recruited, with no age restrictions other than they must have a special need child. Purposeful sampling was used to recruit parents as the researcher wanted participants who can yield significant findings. Snowball sampling was also used, as the snowball sampling method is where the participants recruited other participants to contribute to this research project from among their acquaintances (Kamarudin, 2017). The researcher would ask parents and teachers to tell other parents after obtaining a couple of participants. The snowball sampling method is especially effective in collectivistic cultures such as Malaysia where people get things done through interwoven interpersonal networks (Kamarudin, 2017). Through the snowball method, new participants would be contacted by the researcher. After contacted, participants were asked to document their child's at home reading habits in an open ended questionnaire, and also to participate in a face to face interview, which was audiotaped.

\section{DATA ANALYSIS}

The open ended questionnaires were coded for emergent themes using constant comparative methods. Additionally, the researcher also coded the questionnaire data guided by conceptual categories from the concepts developed through research on preschool children's reading. The questionnaire analysis served to guide the development of follow up interview question protocols. Through coding the questionnaires and finding emergent themes, the researcher was then able to prepare interview questions which contributed to the interview protocol.

Within one week of completing the questionnaires, participants were interviewed using a semi-structured interview method. Interviews were conducted using face to face interview. Interviews were audio-taped and transcribed. After transcribing 
all of the audio tapes, the tapes were disposed of to provide additional protections for participants' confidentiality. Interviews were also coded for emergent themes using constant comparative methods. Using qualitative analysis, the researcher then coded for categories guided by conceptual categories from the concepts developed through preschool children's reading.

\section{Translation and back-translation}

Interviews were translated from Malay language into English. To increase reliability and validity, one half of the questionnaire (open ended section) and one fourth of the interviews will be translated by a native Malay speaker and the English translations will be checked for accuracy. One questionnaire and one interview will also be backtranslated where the English transcript will be given to a native Malay speaker who would then recreate the transcript in Malay by translating from the English version. The two English transcripts (the translated and the back-translated) will be compared for accuracy.

\section{ANALYSIS}

Using qualitative analysis, the interview transcription was coded for emergent themes. Due to the fact that there were ten questions to the interview, the researcher made a table and arranged all the answers into the tables according to question number. This way, the researcher would be able to see how frequent a certain theme is in each question. From the analysis, there were a couple of emergent themes that arose from the data.

In descending order, the themes found most important were implemented into school curriculum, parents should play a bigger role in children's reading habits and early exposure. Under early exposure, there is a subtheme which is better future. Under implemented into school curriculum theme itself there are subthemes which are school should make a reading program and teachers should read more to student. Under implemented into school curriculum and parents should play a bigger role in children's reading habits, there is a cross subtheme which is reading should be included in their daily routine. This is where the subtheme crosses between these two different themes. Also from the qualitative analysis, it was found that $70 \%$ of the parents that state that they read to their children include homework and textbook as part of reading. While the other $30 \%$ are a mixture of comic books and story books.

\section{Implemented Into School Curriculum}

From the open ended questionnaires and face to face interview, $80 \%$ of parents stressed that schools should play a bigger role into implementing early reading habits to their children, though implementing more reading into the school's curriculum.

Mariah said in her open ended section from the questionnaire:

I hope the school can implement this reading culture into children by having a reading competition and give out prizes so that children would be more interested in reading.

Khulsoom said in her interview: 
Schools should have a program where children exchange books between them every day so that they would have a new book every day. They should also be required to bring the book everywhere they go in their free time at school.

Darius said in his interview:

A reading session with the teachers or friends should be implemented into the class schedule.

Dzekry said in his open ended section from the questionnaire:

Teachers should be more helpful and be more aware to children's reading especially to those who has not yet recognized their ABC's.

Donna said in her open ended section from the questionnaire:

Teachers should read different types of story books to the students every day. It could range from fairy tales to folklore or anything from overseas.

\section{Parents Should Play a Bigger Role in Children's Reading Habits}

50 out of 74 (70\%) preschool parents and 20 out of 55 (36\%) of special education parents agreed that parents do need to play a bigger role in implementing reading culture into their children's lives.

Ellyanna said in her open ended section from the questionnaire:

Parents should set a better example when it comes to reading so that children would learn from seeing them.

Mary said in her open ended section from the questionnaire:

Parents should spend more time reading with their children. Parents should bring them to the library or buy books to promote children to be more interested in reading and writing.

Lina said in her open ended section from the questionnaire:

It would be great if it is possible to implement these reading times.

Sally said in her open ended section from the questionnaire:

I agree with the print rich environment, not so that it would make the children interested, but so that it would discipline the parents more to read to their children. I agree it is a good tool but the most important thing is that we need more discipline in reading to our kids.

\section{Early Exposure}

Early exposure is a dominant theme found in the interview and diaries. Early exposure has been frequently brought up under several different topics in the solicited diaries as well as the interview. 44 out of 75 preschool parents and 35 out of 55 special education parents have answered questions using one or more answers with early exposure.

Michelle said in her interview in response to implementing early reading habit:

We should implement early reading habits so that it would be a normal daily routine for our children. 
Dahlya said in her interview in response to implementing early reading habit:

It would be great if children were taught to read as early as 3 years old and hopefully they would love to read.

Majority of parents agree that early exposure to reading is important. They also agreed that early exposure would lead to a brighter future, but Malaysian parents also agreed that it is the school's responsibility to read to their children.

Glory said in her interview in response to implementing early reading habit:

Implementing an early reading culture is very important so that our children would not be left behind in school and also so that our children will gain more in the future.

Ana said in her interview in response to reading habit:

Teachers at school should make students aware about the importance of reading. Children would be more interested and be more respectful if teachers asked them to read. 


\section{REFERENCE}

Braverman, M. T., \& Arnold, M. E. (2008). An evaluator's balancing act: Making decisions about methodological rigor. New Directions for Evaluation, 120, 71-86.

Chapman, J. W. (1988). Cognitive-motivational characteristics and academic achievement of learning disabled children: A longitudinal study. Journal of Educational Psychology, 80, 357-365.

Chapman, J. W., Tunmer, W. E., \& Prochnow, J. E. (2000). Early reading-related skills and performance, reading self-concept and the development of academic self-concept: A longitudinal study. Journal of Educational Psychology, 92, 703-708.

Chew, F. P. (2012). Literacy among the secondary schools students in Malaysia, International Journal of Social Science and Humanity, 2, 546-550.

Cooper, P. M. (2005). Literacy learning and pedagogical purpose in Vivian Paley's 'storytelling curriculum'. Journal of Early Childhood Literacy, 5, 229-251.

Gall, M. D., Gall, J. P., \& Borg, W. R. (2014). Applying Educational Research: How to Read, United

Do, and Use Research to Solve Problems of Practice: $6^{\text {th }}$ Edition. Pearson:

States of America.

Gregory, E. (2001). Sisters and brothers as language and literacy teachers: Synergy between siblings playing and working together. Journal of Early Childhood Literacy, 1(3), 301-322.

Kabuto, B. (2010). Code-switching during parent-child reading interactions: Taking multiple theoretical perspectives. Journal of Early Childhood Literacy, 10, 131-157.

Kamarudin, D. (2017). Methodology (Technology). Publisher: Universiti Malaysia Pahang.

Mol, S. E., Bus, A. G., \& de Jong, M. T. (2009). Interactive book reading in early education: A tool to stimulate print knowledge as well as oral language. Review of Educational Research, 79(2), 979-1007.

Morgan, A. (2005). Shared reading interactions between mothers and pre-school children: Case studies of three dyads from a disadvantaged community. Journal of Early Childhood Literacy, 5, 279-304.

Morgan, P. L., Fuchs, D., Compton, D. L., Cordray, D. S., \& Fuchs, L. S. (2008). Does early reading failure decrease children's reading motivation? Journal of Learning Disabilities, 41, 387-404.

Neuman, S. B. (2010). Lessons from my mother: Reflections on the national early literacy panel report. Educational Researcher, 39 (4), 301-304.

Paley, V. G. (1981). Wally's Stories: Conversations in the Kindergarten. Cambridge, MA: Harvard University Press.

Paley, V. G. (2004). A Child's Work: The Importance of Fantasy Play. Chicago, IL: University of Chicago Press. 
Stanovich, P. J., Jordan, A., \& Perot, J. (1998). Relative differences in academic self-concept and peer acceptance among students in inclusive classrooms. Remedial and Special Education, 19, 120-125.

Swanson, E., Vaughn, S., Wanzek, J., Petscher, Y., Heckert, J., Cavanaugh, C., Kraft, G., \& Tackett, K. (2011). A synthesis of read-aloud interventions on early reading outcomes among preschool through third graders at risk for reading difficulties. Journal of Learning Disabilities, 44(3), 258-275.

The Star Online. (n.d.). Retrieved 2013, from http://thestar.com.my/news/story.asp?file=/2012/8/18/nation/11881979\&sec =nation

Torr, J. (2004). Talking about picture books: The influence of maternal education on four-year-old children's talk with mothers and preschool teachers. Journal of Early Childhood Literacy, 4(2), 181-210.

Wigfield, A., \& Guthrie, J. T. (1997). Relations of children's motivation for reading to the amount and breadth of their reading. Journal of Educational Psychology, 89, 420-432.

Xue, Y., \& Meisels, S. J. (2004). Early literacy instruction and learning in kindergarten: Evidence from the early childhood longitudinal study kindergarten class of 1998-1999. American Educational Research Journal, $41,191-229$ 